ing the relative lengths of polarity epochs in the cores with those of dated ocean floor anomalies. For the period beyond $10 \mathrm{Myr}$ ago, dates were based largely on the correlation of observed radiolarian zones with the tropical radiolarian zoning previously established.

Such dating is easier to describe than to carry out; but within the limitations of the various methods, Hammond and his colleagues go on to plot palaeolatitude (from the measured palaeomagnetic inclinations) as a function of age throughout each core on the assumpthat during the relevant period the geomagnetic field has been axially dipolar. In each case, the variation of palaeolatitude with time indicates northward motion. The overall average rate of movement, based on linear least-squares regression analyses of the latitude-age data, is $8.4 \mathrm{~cm} \mathrm{yr}^{-1}$ during the past 21 Myr. The average, however, conceals a significant mid-period change in motion, for about $12 \mathrm{Myr}$ ago the rate of northward movement seems to have slowed from about 11 to $6 \mathrm{~cm} \mathrm{yr}^{-1}$. This could represent a genuine decrease in the absolute rate of motion, a change in direction (which could reduce the northward component of motion without necessarily reducing the actual rate), or both.

Numbers apart, the important general point demonstrated by Hammond et al. is that the method of reconstructing plate motions using deep sea cores can be made to work as long as the cores cover a sufficiently long interval of time. They also note that in view of the limited number of cores studied and the difficulties in dating them accurately, their own particular results must be regarded as tentative. Nevertheless, they draw attention to the fact that their overall drift rate of $8.4 \mathrm{~cm}$ $\mathrm{yr}^{-1}$ is in excellent agreement with the rate of about $8 \mathrm{~cm} \mathrm{yr}^{-1}$ obtained by Grommé and Vine (Earth planet. Sci. Lett., 17, 159; 1972) from a palaeomagnetic study of Miocene basalts from Midway Atoll.

On the other hand, Hammond and his coworkers do not mention that Winterer (Bull. Am. Ass. Petrol. Geol., 56,$63 ; 1972$ ) concluded (on the basis of eastern Pacific data) that the Pacific plate has been moving northwards at a rate of only $3 \mathrm{~cm} \mathrm{yr^{-1 }}$ for the past $30 \mathrm{Myr}$, nor that Heezen et al. used western Pacific data to obtain an even lower rate of $2 \mathrm{~cm} \mathrm{yr}^{-1}$. But Forristall (Geophys. Res. Lett., 1, 131; 1974) does mention this previous work, and uses it to expand some ideas of his own concerning Pacific motions.

Forristall's ultimate conclusion is that the asthenosphere beneath the central Pacific is about twice as thick as the lithosphere-a result which will cause little surprise insofar as it is in general agreement with majority views favouring shallow convection. But the assumptions and data upon which the conclusion is based are much more contentious. For example, many will surely quarrel not only with Forristall's view that the concept of hot spots fixed with respect to each other has been conclusively rejected but also with his more fundamental assertion that "it is hard to escape the idea that linear chains of volcanic features ... are the expression of isolated subsurface hot spots".

$\mathrm{Be}$ that as it may, the more important point in the present context is that in his calculations Forristall uses the northward drift rates proposed by Winterer and Heezen et al., apparently rejecting the higher rate obtained by Grommé and Vine. It thus becomes clear that not only are different workers obtaining quite different figures for recent Pacific plate motion, the variety of values available provides a basis for wider conclusions. The reasons for the discrepancies in drift rate are not difficult to imagine; but until they are sorted out the confusion is likely to increase.

\section{Observing the millenium}

\section{by John Gribbin}

ON the face of things, the achievement of 1,000 issues of a journal may seem unremarkable by Nature's standardsthis journal is now well into our sixth 'millenium' of continuous publication. But when the journal in question only appears bimonthly at best, and has recently suffered more than most from the rigours of the British three-day week, there is perhaps some excuse for dropping the mask of scientific sobriety for one celebratory issue.

The journal to which I refer is The Observatory, which is the house journal of the Royal Astronomical Society. The sense of humour needed to run such a journal for a body of scientists as free-ranging in their ideas as astronomers is often apparent in ordinary issues of the journal, where sober scientific papers rub cheek by jowl with letters which are sometimes decidedly peculiar (but must presumably be published if they come from Fellows of the RAS?) and with verbatim reports of meetings which are so deadpan that they have on occasion been known to reduce an astronomical coffee break to something approaching hysteria.

To anybody who has been present at the meeting being reported in any particular issue of The Observatory, the favoured game is to spot who has taken the opportunity (offered in the best traditions of scientific accuracy) to change what they actually said at the meeting to what they would have said if they had either remembered, or had time, or read the papers they should have read in advance. Together with the frequent interjections from "A Fellow" (anybody present who was not recognised by the RAS scribes), this makes the meeting reports just about beyond improvement-so it is a pity that the editors of the journal thought it necessary to start their celebratory 1,000 th issue with a spoof meeting report.

The spoof scientific papers are more successful, although most of them hinge upon 'in' jokes which will mean little to non-astronomers (but then, who else will be reading them?). But a couple of contributions deserve at least passing notice from the wider world of science. These are concerned with two newly discovered manifestations of the 11-year cycle which seems to be linked to many terrestrial phenomena, and may be triggered by solar activity. Research into this subject is still seen as a contentious issue in some quarters, and one of the contributors hides behind the pseudonym "Disgusted, Tunbridge Wells" (presumably A. Fellow?). What Disgusted has discovered, among other things, is that an analysis of the number of pages in each issue of The Observatory shows "a suggestion of the eleven-year cycle which occurs in most astronomical data". But the second communication is even more remarkable.

According to Mathews (Observatory, 94, no. $1,000,13 \mathrm{P} ; 1974)$ there is a correlation between sunspot activity and the political "colour" of British governments. Labour governments, it seems, tend to be returned at times of sunspot minimum, and Conservative governments at times of sunspot maximum. Best of all, in a prediction made before the most recent British election but only now appearing in print, Mathews said "regions of political instability may well be triggered in the next few months, resulting in the election of a Labour Government", and also predicted "the continuation of the Liberal revival". Those predictions, of course, may well be considered still relevant today, and if $\mathrm{Mr}$ Harold Wilson is a reader of The Observatory, there might well be another election in Britain in the very near future.

This area of sunspot research is clearly an important field of astronomy today (see Nature 246, 453; 1973). If there are still doubters who are unconvinced of the reality of the solarterrestrial links let them ponder on a quote from The Observatory of 1877 $(1,370)$ : “M. Tempel supposes that the spiral shapes (of Nebulae) are only creatures of fantasy". 